\title{
Research on Intelligent Services Mode for Inland Ships
}

\author{
Qichao Wang ${ }^{1, a}$, Jiangling $\mathrm{HaO}^{2, \mathrm{~b}}$ and Xiaolin Wang ${ }^{3, \mathrm{c}}$ \\ ${ }^{1}$ Navigation College, Dalian Maritime University, Dalian, 116026, China \\ ${ }^{2}$ Navigation College, Dalian Maritime University, Dalian, 116026, China \\ ${ }^{3}$ Foreign Languages College, Dalian Maritime University, Dalian, 116026, China \\ a18941132350@163.com, b986856892@qq.com, '1012698646@qq.com
}

\begin{abstract}
Keywords: intelligent services, whole file, location file, water level prediction, multiple linear regression analysis
\end{abstract}

\begin{abstract}
The purpose of this paper is to propose a new intelligence services mode. The authors analyze the advantages of this services mode compared with the traditional ones. Design the structure of whole file and location file involving head information and body information, and take water depth data as an example to show a part of them. By applying multiple linear regression analysis, predict future water level based on a large amount of real-time and historical water level data. $\mathrm{R}$ language program shows that forecasting results are good.
\end{abstract}

\section{Introduction}

Location big data is a very significant component of big data. River location big data is related to inland shipping elements. Inland electronic navigational chart (IENC) is the extension of electronic navigational chart (ENC) in the inland river [1]. At present, China's IENC is still in use of the traditional ENC services mode. With the development of mobile Internet, smart phones and shipborne equipment, river location big data and intelligent services have become important parts of inland shipping information industry. This traditional, non-intelligent IENC services mode has been unable to meet the needs of inland ships.

\section{New Intelligent Services Mode}

Intelligent services are the abilities to automatically identify the users' explicit and implicit needs and meet the needs for services in an active, highly efficient, safe and green way [2]. For inland ships, new intelligence services mode is divided into whole file mode and location file mode. Sent the static data in the original IENC file (wharf, shoreline, e.g.) to the ships directly. It is downloaded only for once and used in the voyage without updating. Take the dynamic data (water depth, abnormal buoy, e.g.) out of the original IENC file and combine the dynamic data with those collected from such data sources as meteorological center, VTS center and AIS base station as river location big data to conduct data mining and data analysis. The whole process of new intelligence services mode is shown in Fig. 1.

New intelligent services mode has the following advantages: (1) Dynamics. The update cycle is short, so it can reflect such river location big data as water depth and abnormal buoy in real time and in a dynamic way. (2) Intelligence. The whole services process is active and users' explicit and implicit needs are automatically identified at backstage. It can provide boatmen services without downloading and updating. (3) High value. The services are in high value and the boatmen can use them directly without calculation and processing. (4) Accuracy. Whole file and location file contain the corresponding whole symbols and location symbols, which can more accurately and evidently remind the boatmen. 


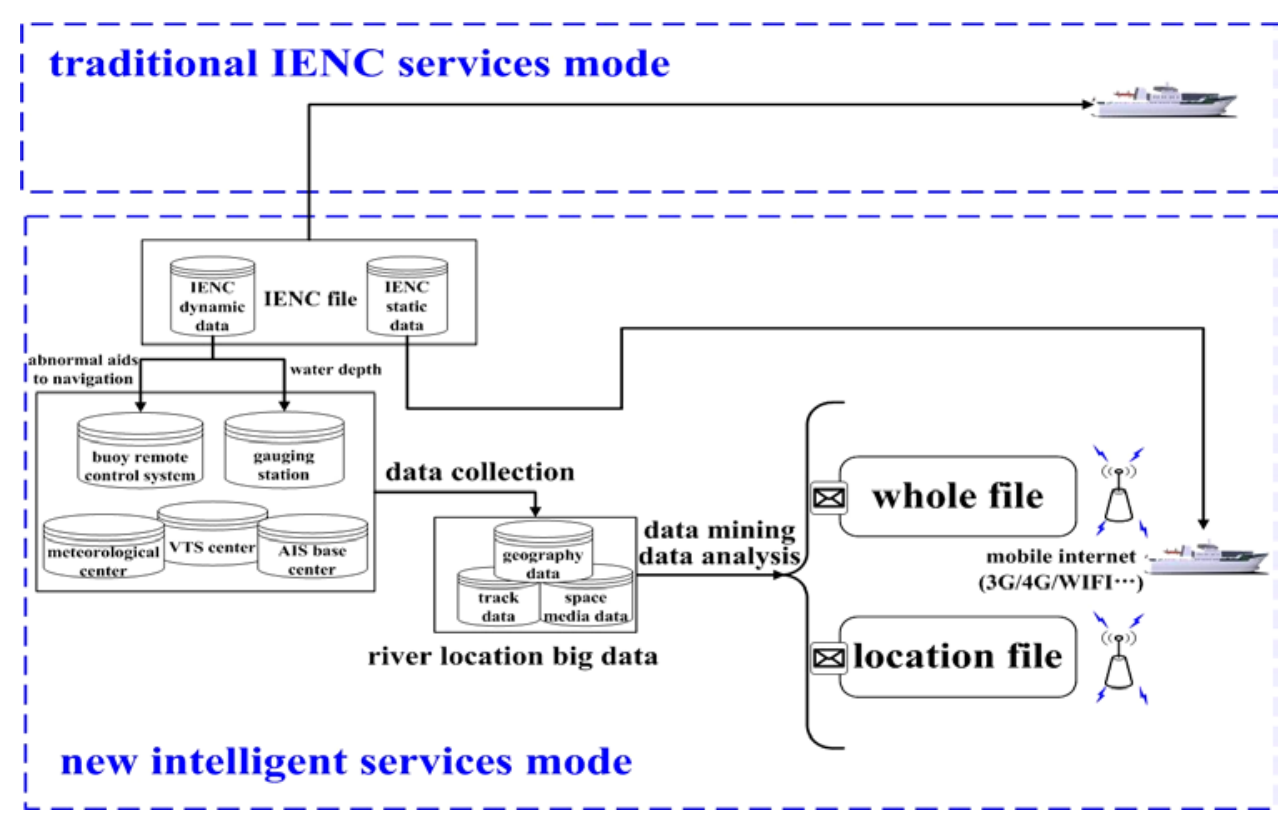

Fig. 1 The whole process of new intelligent services mode

\section{Whole File Mode}

Whole file is a form that provides services of one whole voyage for boats from departure port A to destination port B in accordance with needs and in an initiative way. It's a "macro" and directional services mode. The whole voyage updates for $\mathrm{N}$ times. Whole file is divided into head information and body information. Head information is shown in Table 1. Body information is shown in Fig. 2.

Take water depth data as an example, Table 2 shows the structure of most shallow water depth in whole file.

Table 1 Whole file head information

\begin{tabular}{cccc}
\hline No. & Variable & Type & Remarks \\
\hline 1 & whole file title & char & \\
2 & survice leg & char & port A to port B \\
3 & survice object & char & ship’s name \\
4 & issue date & date & YYYY-MM-DD HH:MM:SS \\
5 & update interval & date & HH:MM:SS \\
6 & issue institution & char & \\
7 & version & integer & \\
\hline
\end{tabular}

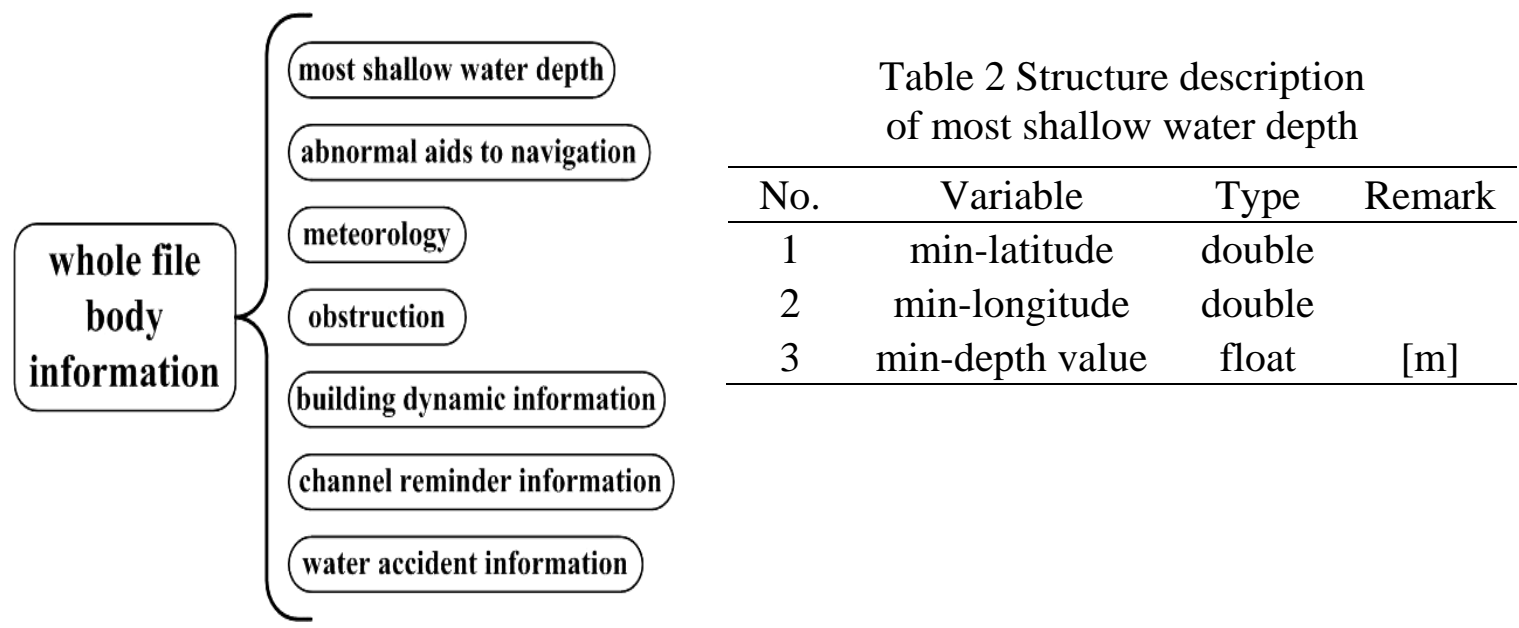

Fig. 2 Whole file body information 


\section{Location File Mode}

Location file is a form that provides all the services for boats at a certain time around the ship's location. It is a "micro" services mode in real time and in a dynamic way. Time interval of location services is constantly changing and is identified automatically. Location file is divided into head information and body information. Head information is shown in Table 3. Body information is shown in Fig. 3.

Take water depth data as an example, Table 4 shows the structure of safe navigable waters in location file.

Table 3 Location file head information

\begin{tabular}{cccc}
\hline No. & Variable & Type & Remarks \\
\hline 1 & survice object & char & ship’s name \\
2 & location latitude & double & \\
3 & location longitude & double & \\
4 & issue date & date & YYYY-MM-DD HH:MM:SS \\
5 & update interval & date & MM:SS \\
\hline
\end{tabular}

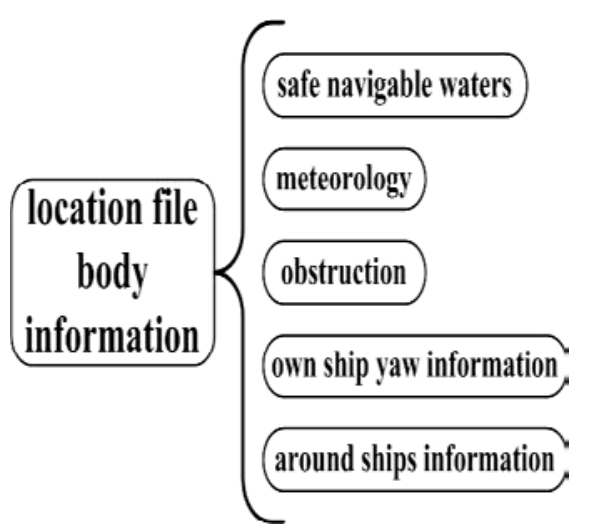

Table 4 Structure description of safe navigable waters

Fig. 3 Location file body information

\begin{tabular}{|c|c|c|c|}
\hline No. & Variable & Type & Remarks \\
\hline 1 & nchains & byte & number of edges \\
\hline 2 & achains & chain* & $\begin{array}{l}\text { edge pointer, description } \\
\text { of each side }\end{array}$ \\
\hline 3 & coverage & rect & coverage area \\
\hline
\end{tabular}

\section{Water Level Prediction Based on Regression Analysis}

In a variety of river location big data, water level data is very important. It's the basis of reasonable stowage, across the shoal, real-time water depth display, across the bridge, e.g. [3]. By calculation, we can get water depth data from water level data.

The study of multiple linear regression analysis is the relationship among the dependent variable and multiple independent variables [4]. This paper applies multiple linear regression analysis to predict future water level based on a large amount of real-time and historical water level data.

Set $p$ independent variables $x_{j}(j=1,2, \ldots, p)$, then multiple linear regression model is

$$
y=\beta_{0}+\beta_{1} x_{1}+\beta_{2} x_{2}+\ldots+\beta_{p} x_{p}+\varepsilon .
$$

$\beta_{0}, \beta_{1}, \beta_{2}, \ldots, \beta_{p}$ are $p+1$ unknown parameters and $\beta_{0}$ is constant term. $\beta_{1}, \beta_{2}, \ldots, \beta_{p}$ are called partial regression coefficient. $\varepsilon$ is random error, $\varepsilon \sim N\left(0, \sigma^{2}\right)[5]$.

Select 4 continuous gauging stations: Ma'anshan, Banqiao, Nanjing and Yangzi in the Yangtze River. Obtain the water level data per hour of the four stations from June $1^{\text {st }}, 2014$ to April $30^{\text {th }}, 2015$. Set the difference between the next 1 hour water level of Nanjing and the current water level as $y$. The difference between the current water level of Nanjing and the previous 1 hour water level is $x_{1}$. The difference between the current water level of Ma'anshan and the previous 1 hour is $x_{2}$. The difference between the current water level of Banqiao and the previous 1 hour is $x_{3}$. The difference between the current water level of Yangzi and the previous 1 hour is $x_{4}$. Select $\mathrm{R}$ language as the data analysis and mining tool to realize this process. At last, R program running results are shown in Fig. 4. 


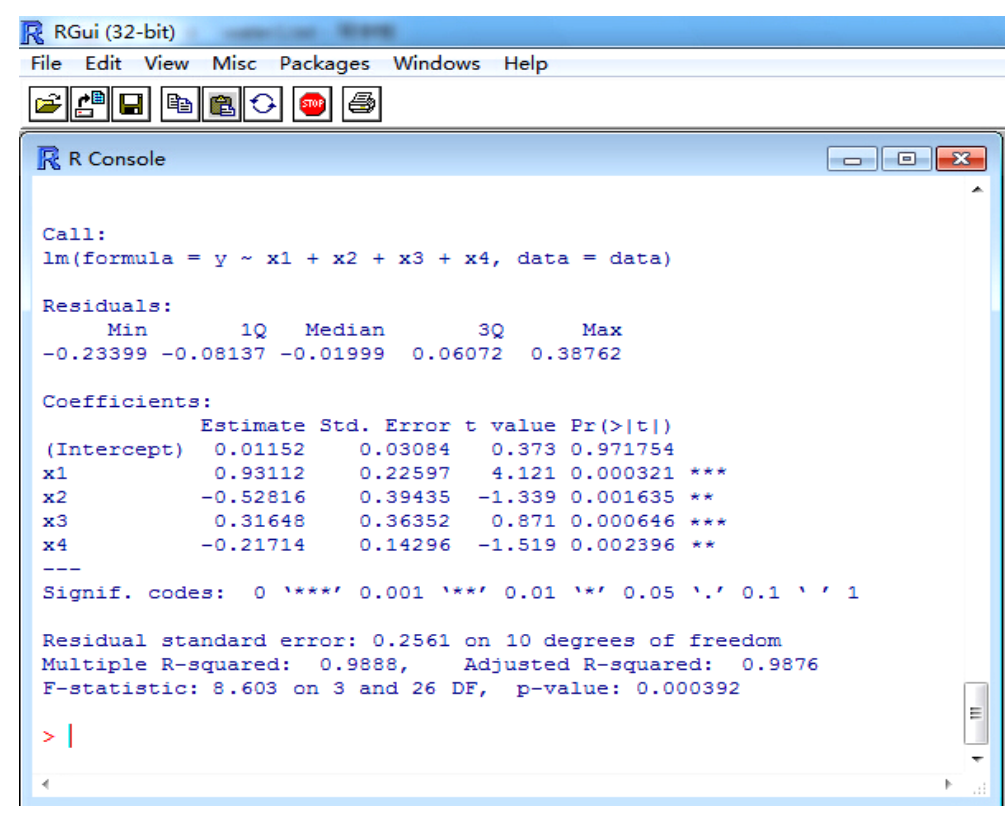

Fig. $4 \mathrm{R}$ program running results

Fig. 4 shows that $R^{2}$ is close to 1 , which indicates the regression model is close to the actual situation. P-value of F-statistic is less than 0.05 , so linear relationship exists between $y$ and $x_{j}(j=1$, $2, \ldots, p) . \mathrm{P}_{\mathrm{r}}$ of $\beta_{0}$ is more than 0.05 , so cancel it [6]. Get the regression model is

$y=0.93112 x_{1}-0.52816 x_{2}+0.31648 x_{3}-0.21714 x_{4}$.

(2)

\section{Conclusions}

In this paper, a new intelligence services mode is proposed.

a. Analyze the advantages of this services mode.

b. Design the structure of whole file and location file and show water depth data part of them.

c. Apply multiple linear regression analysis to predict future water level by using a large amount of real-time and historical water level data, and $\mathrm{R}$ program shows that forecasting results are good.

\section{Acknowledgements}

This work is supported by Research on Key Technology of Integrated Information Service of the Yangtze River Golden Waterway (802070), the Fundamental Research Funds for the Central Universities (3132014309) and Development Research on Tianjin Nangang Harbor District Ship Safety Supervision and Management (851238).

\section{References}

[1] Inland ENC Harmonization Group. Inland Electronic Navigational Chart Encoding Guide Edition 3.1 (2008).

[2] Information on http://baike.baidu.com/view/7991751.htm.

[3] Xi Zhou, Qing Shi: Transportation Enterprise Management. Vol. 2 (2015), p. 36-37 (In Chinese).

[4] Liping Ma: Regression Analysis (Machinery Industry Press, Beijing 2014) (In Chinese).

[5] Shiyu Li, Fei Zhang, Zhenglin Wang: Data Analysis : R language (Electronics Industry Press, Beijing 2014) (In Chinese). 
[6] Paul Teetor: $R$ language Classical Examples, translated by Hongcheng Li, Wenjia Zhu and Yicheng Shen (Machinery Industry Press, Beijing 2013) (In Chinese). 